\title{
Response to neoadjuvant chemotherapy and survival of children and adolescents with high-grade osteosarcoma treated based on the EURAMOS-1 protocol
}

\author{
Amaranto Suárez-Mattos ${ }^{1,2 *}$, Federico Arroyave ${ }^{1,2}$, Ana M. Infante ${ }^{1,2}$, Carlos Narváez ${ }^{1,2}$, Camilo Soto $^{3}$, \\ Luis Gómez ${ }^{3}$, and Javier Amaya-Nieto ${ }^{4}$ \\ ${ }^{1}$ Clínica de Oncología Pediátrica, Instituto Nacional de Cancerología; ${ }^{2}$ Universidad Militar Nueva Granada de Colombia; ${ }^{3}$ Clínica de Ortopedia \\ Oncológica, Instituto Nacional de Cancerología; ${ }^{4}$ Instituto de Investigaciones Clínicas, Universidad Nacional de Colombia. Bogotá D. C., Colombia
}

\begin{abstract}
Background: High-grade osteosarcoma is the most common malignant bone tumor in children and adolescents. This study aimed to evaluate the histologic response to neoadjuvant chemotherapy and overall and event-free survival rates in patients $<21$ years of age with a diagnosis of conventional osteosarcoma. Methods: We conducted an analytical and observational study of a cohort of patients < 21 years old with a diagnosis of conventional osteosarcoma treated with the OS INC-2009 protocol (based on EURAMOS-1). Descriptive analysis was performed, and overall and event-free survival rates were calculated by the Kaplan-Meier method. Results: Between April 2009 and October 2016, 84 patients with conventional osteosarcoma (mean age $13.5 \pm 3.2$ years) were admitted. Metastatic disease at diagnosis was observed in 36 patients (42.8\%). Of the 41 patients who received neoadjuvant chemotherapy (50.6\%), 15 (36.6\%; confidence interval [95\% Cl]: 49.9-75.6) were classified as good responders and 26 (63\%; 95\% Cl: 22.5-58.0) as poor responders. The 5-year overall and event-free survival rates in good responders were $88.8 \%$ (95\% Cl: 43.3-98.3) and 81.4\% (95\% Cl: 43.5-95.0); in poor responders it was $66.5 \%$ (95\% Cl: 40.7-83.1) and 31.4\% (95\% Cl: 13.8-50.7), respectively. Conclusions: Good responders' evaluation of histologic response to neoadjuvant chemotherapy showed improved overall and event-free survival rates. Specialized centers with multidisciplinary and comprehensive management are required to make the application of high-toxicity protocols feasible.
\end{abstract}

Keywords: Osteosarcoma. Chemotherapy. Neoadjuvant chemotherapy. Survival.

\section{Respuesta a la quimioterapia neoadyuvante y supervivencia de niños y adolescentes con osteosarcoma de alto grado tratados de acuerdo con el protocolo EURAMOS-1}

\section{Resumen}

Introducción: El osteosarcoma de alto grado es el tumor óseo maligno más común en niños y adolescentes. El objetivo de este trabajo fue evaluar la respuesta histológica a la quimioterapia neoadyuvante y la supervivencia global y libre de eventos en pacientes menores de 21 años con diagnóstico de osteosarcoma convencional. Métodos: Se llevó a cabo un estudio observacional analítico de una cohorte de pacientes menores de 21 años con diagnóstico de osteosarcoma convencional tratados con el protocolo OS INC-2009 (basado en EURAMOS-1). Se realizó el análisis descriptivo y se calcularon la su-

\section{Correspondence:}

*Amaranto Suárez-Mattos

E-mail: asuarez@cancer.gov.co
Date of reception: 03-05-2021

Date of acceptance: 26-09-2021

DOI: 10.24875/BMHIM.21000087
Available online: 24-01-2022

Bol Med Hosp Infant Mex. 2022;79(1):17-25

www.bmhim.com (http://creativecommons.org/licenses/by-nc-nd/4.0/). 
pervivencia global y la supervivencia libre de eventos por el método de Kaplan-Meier. Resultados: Entre abril de 2009 y octubre de 2016 se analizaron 84 pacientes con osteosarcoma convencional, cuya edad promedio fue de 13.5 años (desviación estándar: \pm 3.2). La enfermedad metastásica al diagnóstico se observó en 36 pacientes (42.8\%). De los 41 (50.6\%) pacientes que recibieron terapia neoadyuvante, 15 (36.6\%; intervalo de confianza del 95\% [IC95\%]: 49.9-75.6) se clasificaron como buenos respondedores y 26 (63\%; IC95\%: 22.5-58.0) como malos respondedores. Las supervivencias global y libre de eventos a 5 años en los buenos respondedores fueron del 88.8\% (IC95\%: 43.3-98.3) y el 81.4\% (IC95\% 43.5-95.0), $y$ en los malos respondedores fueron del 66.5\% (IC95\%: 40.7-83.1) y el 31.4\% (IC95\%: 13.8-50.7), respectivamente. Conclusiones: La evaluación de la respuesta histológica a la quimioterapia neoadyuvante de los pacientes buenos respondedores muestra unas mejores supervivencias global y libre de eventos. Se requieren centros especializados con manejos multidisciplinarios e integrales para hacer factible la aplicación de protocolos con alta toxicidad.

Palabras clave: Osteosarcoma. Quimioterapia. Neoadyuvante. Supervivencia.

\section{Introduction}

High-grade osteosarcoma is the most frequent malignant bone tumor in children and adolescents. It accounts for approximately $2.5 \%$ of all types of cancer in children $<15$ years and $4.2 \%$ in young people aged 15-19 years ${ }^{1,2}$. The annual incidence rate varies between 3.5 and 8.8 cases/million in children $<15$ and 15-19 years, respectively, clearly demonstrating that this tumor mainly affects the second decade of life. The introduction of multi-agent chemotherapy in the early 1970s and complete surgical resection became the standard treatment, improving 5-year event-free survival (EFS) from $20 \%$ to $60 \%$ in localized osteosarcomas. However, there has been no progress in improving survival in the last 30 years $^{3-5}$. The European and American Osteosarcoma Studies (EURAMOS) collaboration, founded in 2001 , is an initiative of four international groups [Children's Oncology Group (COG), Cooperative German-Austrian-Swiss Osteosarcoma Study Group (COSS), European Osteosarcoma Intergroup (EOI), and Scandinavian Sarcoma Group (SSG)] established to conduct randomized clinical trials and improve osteosarcoma outcomes ${ }^{6}$.

Initial studies from Huvos et al. ${ }^{7}$ explored the histologic response to neoadjuvant chemotherapy in the 1970s and showed an association between the degree of tumor necrosis in the surgical specimen (en bloc tumor resection) and improved survival ${ }^{1,8,9}$. In three subsequent studies, EOI compared the two-drug regimen, cisplatin plus adriamycin, with the same treatment strategy and the addition of methotrexate; overall survival at 5 and 9 years was 56\% (95\% confidence interval (Cl) $53 \%-59 \%)$ and $52 \%(95 \% \mathrm{Cl} 49 \%-55 \%)$, respectively, but no statistically significant differences were found between the two treatment groups. However, a good response to neoadjuvant chemotherapy was found to be associated with improved survival ${ }^{1,10-13}$.
The first EURAMOS-1 study, initiated in 2005 and closed in 2011, investigated treatment options based on histologic response to preoperative chemotherapy. The study defined as standard neoadjuvant chemotherapy the combination of methotrexate, adriamycin, and cisplatin (MAP) for all patients and good responders; in poor responders, ifosfamide plus etoposide (MAPIE) was added in postoperative treatment. At 3 and 5 years, survival was $79 \%(95 \% \mathrm{Cl} 77 \%-81 \%)$ and $71 \%(95 \% \mathrm{Cl}$ $68 \%-73 \%$ ), respectively. Poor response to preoperative chemotherapy was shown to be strongly associated with worse event-free survival (hazard ratio $(\mathrm{HR})=2.13$; $95 \% \mathrm{Cl} 1.76 \%-2.58 \%$ ) and overall survival ${ }^{12-14}$.

In this study, we report the demographic and clinical characteristics, the evaluation of the histological response to neoadjuvant chemotherapy, the overall and event-free survival rates of patients $<21$ years of age with a diagnosis of high-grade osteosarcoma who received treatment with the OS-INC 2009 protocol (based on EURAMOS-1) and were treated at the National Cancer Institute (INC, for its Spanish acronym).

\section{Methods}

\section{Study design and population}

We conducted a retrospective observational cohort study that included all patients under 21 years of age with a histologically confirmed diagnosis of conventional high-grade osteosarcoma, who had not received previous treatment and who were treated with the OS INC-2009 protocol (based on EURAMOS-1) ${ }^{5}$ at the INC (Bogotá, Colombia) between April 1, 2009, and October 31, 2016. All patients required a biopsy to confirm the histologic diagnosis, which was analyzed by the oncologic pathology group of the institution. Patients in whom more than $80 \%$ of the information on the studied 
variables could not be obtained were excluded. The research project was evaluated and approved by the INC Research Ethics Committee.

\section{Initial evaluation and follow-up protocol}

Patients underwent an initial diagnostic evaluation on admission, including clinical history and physical examination, blood chemistry to determine alkaline phosphatase levels, and renal and liver function tests. In addition, adequate bone marrow function (leukocytes $\geq 3000 / \mathrm{mm}^{3}$, absolute neutrophils $>500 / \mathrm{mm}^{3}$, platelets $\geq 100,000 / \mathrm{mm}^{3}$ ), renal function with glomerular filtration $\geq 70 \mathrm{ml} / \mathrm{min}$, cardiac function with shortening fraction $\geq 28 \%$ or left ventricular ejection fraction $(\mathrm{LVEF}) \geq 70 \%$ were required. Before taking the biopsy, simple X-ray and simple and contrasted magnetic resonance imaging (MRI) of the involved bone, simple computed axial tomography (CT) of the thorax, and bone scintigraphy were performed. An open or percutaneous biopsy of the compromised bone was performed. In patients in whom a biopsy had already been performed on admission, the respective paraffin blocks and histological slides were requested for review by the INC pathology group to confirm the diagnosis. Before each cycle of chemotherapy with cisplatin, glomerular filtration scintigraphy was performed and, before doxorubicin administration, LVEF was measured. Evaluation prior to local surgical control was performed with MRI of the primary tumor, simple CT of the thorax, and bone scintigraphy.

Patient follow-up consisted of a physical examination with alkaline phosphatase measurement and chest X-ray every 3 months and chest CT every 6 months during the first year. Subsequently, patients were monitored with simple chest CT every 6 months until completing 5 years from diagnosis. Histologic evaluation of the response to chemotherapy was performed on the surgical specimen of the primary tumor after tumor resection. The response grading system was used, classifying patients with tumor necrosis $\geq 90 \%$ as good responders and $<90 \%$ tumor necrosis as poor responders, using the method of regional mapping of viable and non-viable tumors previously described by Picci et al ${ }^{8}$.

\section{Treatment with OS-INC 2009 protocol}

All patients received the same chemotherapy regimen (MAP) preoperatively for 10 weeks. The MAP regimen consisted of cisplatin $60 \mathrm{mg} / \mathrm{m}^{2} \mathrm{sc}$ on days 1 and 2 and doxorubicin $37.5 \mathrm{mg} / \mathrm{m}^{2} \mathrm{sc}$ on days 1 and 2 , during weeks 1 and 6 of treatment and high-dose methotrexate $12 \mathrm{~g} / \mathrm{m}^{2} \mathrm{sc}$ as a 4-hour infusion on weeks 4,5 , 9 and 10. Salvage was performed with folinic acid $15 \mathrm{mg} / \mathrm{m}^{2} \mathrm{sc}$ initiated 24 hours after starting methotrexate and continued until the serum drug level was $<0.1 \mu \mathrm{mol} / \mathrm{L}$. Local control surgery was planned for week 11. Subsequently, good responders to chemotherapy received four cycles of MAP similar to the cycles of neoadjuvant chemotherapy. Poor responders received seven cycles of chemotherapy with MAPIE (high-dose methotrexate, doxorubicin, cisplatin, ifosfamide, etoposide). In addition, cisplatin, doxorubicin, and methotrexate were administered at the same doses applied preoperatively and ifosfamide $2.8 \mathrm{~g} / \mathrm{m}^{2} \mathrm{sc}$ for 5 days at weeks 17,25 , and 33 . In addition, mesna was administered in isodose $2.8 \mathrm{~g} / \mathrm{m}^{2} \mathrm{sc} /$ day in continuous infusion $x 5$ days with etoposide $100 \mathrm{mg} / \mathrm{m}^{2} \mathrm{sc} /$ day at weeks 17,25 , and 33 . The treatment regimen and chemotherapy doses are shown in Figure 1.

\section{Outcome}

Two primary outcomes were considered: EFS, which was defined as the time from the date of the first consultation to the date of the first event (first relapse or death, whichever occurred first), and overall survival (OS), which was defined as the time from the first consultation to the date of death from any cause.

\section{Statistical analysis}

Descriptive statistics of the sociodemographic and clinical characteristics of the study population were performed with measures of central tendency and dispersion depending on the nature of each variable. For bivariate analysis, patients with good and poor responses to treatment were used as subgroups. The corresponding statistical tests were performed. The level of statistical significance used was 0.05 . Confidence intervals were estimated at $95 \%$.

For the survival analysis, in which survival time and event-free time were used as an outcome, survival curves were compared using the nonparametric Kaplan-Meier method and the survival function for the total cohort and for patients who did not present the event. Survival time was calculated from the time of diagnosis to death. Patients who did not present any event at the time of data collection were censused at the date of the last control. Survival functions were compared using the log-rank sum test. All 


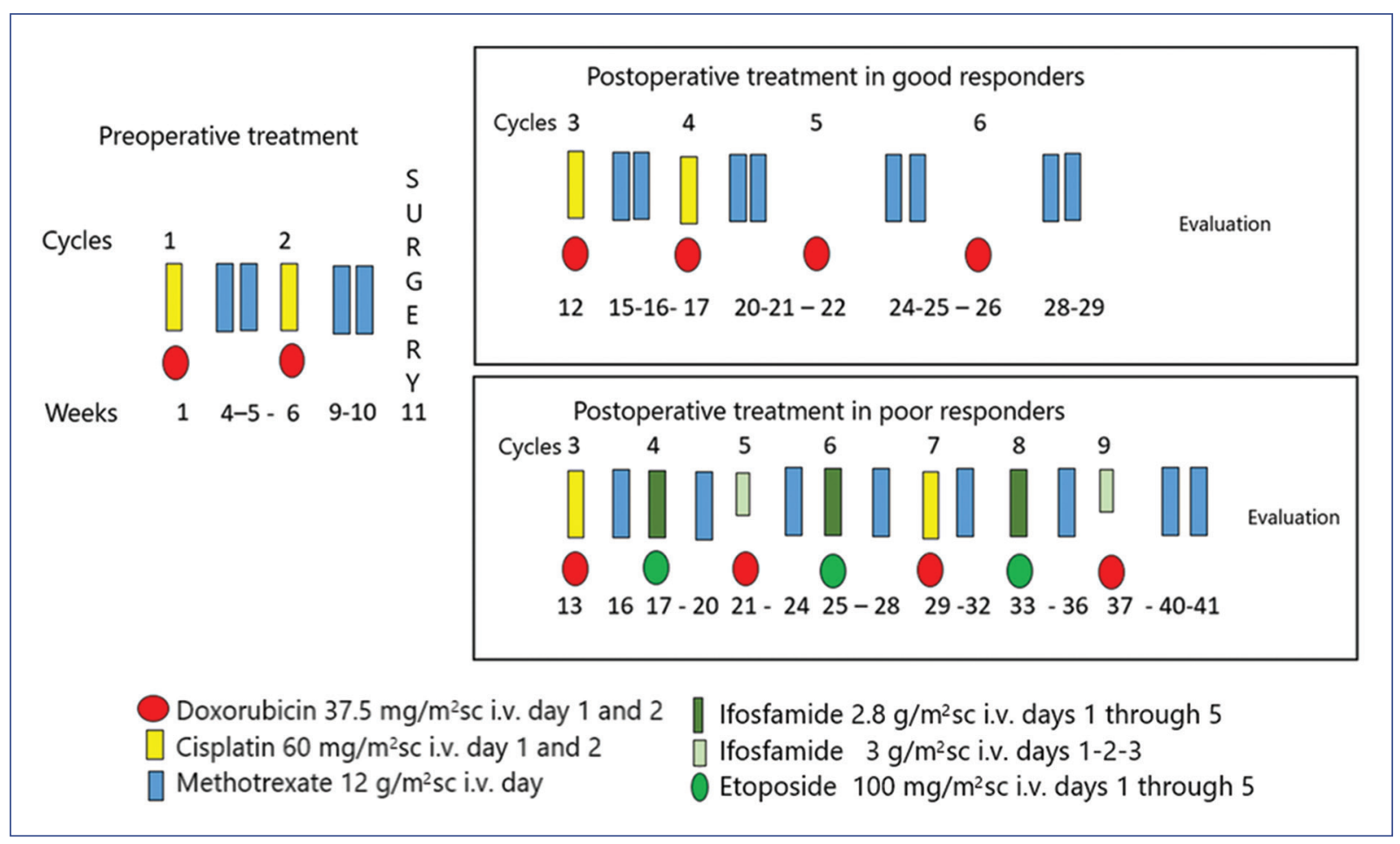

Figure 1. OS-INC 2009 treatment scheme at the Instituto Nacional de Cancerología.

calculations were performed with $\mathrm{R}$ statistical software version 3.0.1.

\section{Results}

Between January 2009 and December 2016, 90 patients were admitted with conventional high-grade osteosarcoma, of which six patients $(6.66 \%)$ were excluded due to lack of data in $80 \%$ of the variables considered in the study. To analyze histologic response to neoadjuvant chemotherapy, we included a cohort of 84 patients with conventional high-grade osteosarcoma of any location, with or without metastases at diagnosis, of whom 41 (50.6\%) received neoadjuvant chemotherapy. No significant differences were found between good and poor responders to neoadjuvant chemotherapy, except in the number of patients with metastases at diagnosis, where a higher proportion was observed in the group with poor response to treatment. Table 1 shows the baseline demographic and clinical characteristics of the cohort of good and poor responders to neoadjuvant chemotherapy.

The mean age was 13.5 years (standard deviation (SD): \pm 3.3 . . Male sex accounted for $59.5 \%$ (50/81). All patients presented pain as the initial symptom, and $89 \%$ presented a mass at the primary tumor site. The most frequent location of the primary tumor was the lower extremity, mainly affecting the distal third of the femur and the proximal third of the tibia and fibula. Of the histological subtypes, the most frequent was osteoblastic osteosarcoma (63\%), followed by chondroblastic and mixed types. Metastatic disease at diagnosis in the entire cohort was observed in $36 / 81$ patients $(42.8 \%)$. In the 36 patients with metastases, the most frequent location was the lung: in 30 patients as a single location and five with combined lung and bone metastases $(97 \%)$, only one patient had isolated bone metastases.

Of the 41 patients who received neoadjuvant chemotherapy, 15 (36.6\%, 95\% Cl 49.9-75.6) were classified as good responders and $26(63 \%, 95 \% \mathrm{Cl} 22.6-53.0)$ as poor responders (Table 2). As can be seen in Table 1, the disease was localized at diagnosis in the majority of good responders [13/15 (86\%)], whereas in the poor responder group, the proportion of patients with localized disease and metastases was similar ( $42.3 \%$ vs. $57.7 \%$ ). However, $84 \%$ of patients with metastases at diagnosis were poor responders.

\section{Outcome}

Table 2 presents the outcomes of the 41 patients who received treatment with neoadjuvant chemotherapy. Of 
Table 1. Clinical characteristics of the complete cohort and of the patients who received neoadjuvant therapy

\begin{tabular}{|c|c|c|c|c|c|}
\hline Characteristics & $\begin{array}{l}\text { Complete cohort } \\
\qquad(\mathrm{n}=84)\end{array}$ & $\begin{array}{l}\text { Neoadjuvant } \\
\text { chemotherapy } \\
\quad(n=41)\end{array}$ & $\begin{array}{l}\text { Good response } \\
\qquad(n=15)\end{array}$ & $\begin{array}{c}\text { Poor response } \\
\quad(n=26)\end{array}$ & $p$-values \\
\hline Age (years), mean (SD) & $13.5(3.3)$ & $13.4(2.9)$ & $14(2.9)$ & $13.07(2.9)$ & 0.281 \\
\hline $\begin{array}{l}\text { Sex, n (\%) } \\
\text { Male } \\
\text { Female }\end{array}$ & $\begin{array}{l}50(59.5) \\
34(40.4)\end{array}$ & $\begin{array}{l}22(53.6) \\
19(46.3)\end{array}$ & $\begin{array}{l}9(40.9) \\
6(31.5)\end{array}$ & $\begin{array}{l}13(59.1) \\
13(68.4)\end{array}$ & 0.536 \\
\hline $\begin{array}{l}\text { Residence, n (\%) } \\
\text { Urban } \\
\text { Rural }\end{array}$ & $\begin{array}{l}48(60.7) \\
31(39.2)\end{array}$ & $\begin{array}{l}26(72.2) \\
10(27.7)\end{array}$ & $\begin{array}{l}9(34.6) \\
3(30.0)\end{array}$ & $\begin{array}{l}17(65.3) \\
7(70.0)\end{array}$ & 0.560 \\
\hline $\begin{array}{l}\text { Clinical manifestations, n (\%) } \\
\text { Pain } \\
\text { Tumor } \\
\text { Erythema } \\
\text { Functional disability } \\
\text { Pathological fracture }\end{array}$ & $\begin{array}{l}81(100) \\
75(89.2) \\
11(13.1) \\
46(54.7) \\
8(9.5)\end{array}$ & $\begin{array}{c}41(100) \\
37(90.2) \\
5(12.2) \\
21(51.2) \\
3(7.3)\end{array}$ & $\begin{array}{c}15(100) \\
11(73.3) \\
3(20.0) \\
10(66.6) \\
2(7.6)\end{array}$ & $\begin{array}{c}26(100) \\
26(100) \\
2(7.69) \\
11(42.3) \\
1(6.6)\end{array}$ & $\begin{array}{c}0.013^{*} \\
0.249 \\
0.119 \\
0.701\end{array}$ \\
\hline $\begin{array}{l}\text { Location, n (\%) } \\
\text { Femur } \\
\text { Tibia } \\
\text { Humerus } \\
\text { Fibula } \\
\text { Pelvis } \\
\text { Other }\end{array}$ & $\begin{array}{l}53(63.1) \\
18(21.4) \\
4(4.7) \\
6(7.1) \\
2(2.3) \\
1(1.1)\end{array}$ & $\begin{array}{c}29(70.7) \\
10(24.3) \\
1(2.44) \\
1(2.44) \\
0 \\
0\end{array}$ & $\begin{array}{c}10(34.4) \\
4(40.0) \\
1(100) \\
0 \\
0 \\
0\end{array}$ & $\begin{array}{c}19(65.5) \\
6(60.0) \\
0 \\
1(100) \\
0 \\
0\end{array}$ & 0.708 \\
\hline $\begin{array}{l}\text { Histologic type, n (\%) } \\
\text { Osteoblastic } \\
\text { Chondroblastic } \\
\text { Fibroblastic } \\
\text { Mixed } \\
\text { Telangiectatic } \\
\text { Small cell } \\
\text { Parosteal } \\
\text { No information }\end{array}$ & $\begin{array}{c}53(63.1) \\
7(8.3) \\
2(2.38) \\
7(8.3) \\
4(4.7) \\
1(1.1) \\
3(3.5) \\
7(8.3)\end{array}$ & $\begin{array}{c}28(68.2) \\
1(2.44) \\
1(2.44) \\
3(7.3) \\
2(4.8) \\
0 \\
1(2.44) \\
5(12.2)\end{array}$ & $\begin{array}{c}8(28.5) \\
1(100) \\
0 \\
1(33.3) \\
1(50) \\
0 \\
1(100) \\
3(60.0)\end{array}$ & $\begin{array}{c}20(71.4) \\
0 \\
1(100) \\
2(66.6) \\
1(50) \\
0 \\
0 \\
2(40)\end{array}$ & 0.304 \\
\hline $\begin{array}{l}\text { Stage, n (\%) } \\
\text { IIA } \\
\text { IIB } \\
\text { III }\end{array}$ & $\begin{array}{c}3(3.5) \\
45(53.5) \\
36(42.8)\end{array}$ & $\begin{array}{c}1(2.4) \\
27(65.8) \\
13(31.7)\end{array}$ & $\begin{array}{c}1(100) \\
12(44.4) \\
2(15.3)\end{array}$ & $\begin{array}{c}0 \\
15(55.5) \\
11(84.6)\end{array}$ & 0.590 \\
\hline $\begin{array}{l}\text { Metastases, n (\%) } \\
\text { Yes } \\
\text { No }\end{array}$ & $\begin{array}{l}36(42.8) \\
48(57.1)\end{array}$ & $\begin{array}{l}13(31.7) \\
28(68.2)\end{array}$ & $\begin{array}{c}2(15.3) \\
13(46.4)\end{array}$ & $\begin{array}{l}11(84.6) \\
15(53.5)\end{array}$ & 0.055 \\
\hline
\end{tabular}

SD, standard deviation.

these patients, $15(36.6 \%)$ were good responders, and $26(63.4 \%)$ showed a poor histologic response. Table 3 shows survival according to histologic response to treatment with preoperative chemotherapy and stage of disease at diagnosis. The OS and 5-year EFS in good responders was $88.8 \%(95 \% \mathrm{Cl} 43.3-98.3)$ and $81.4 \%$ (95\% Cl 43.5-95.0), respectively; in poor responders, $66.5 \%(95 \% \mathrm{Cl} 40.7-83.1)$ and $31.4 \%(95 \% \mathrm{Cl} 13.8-50.7)$, respectively. Patients with localized disease at diagnosis had an OS and 5-year EFS of $78.4 \%(95 \% \mathrm{Cl}$ $54.7-90.6)$ and $60.0 \%(95 \% \mathrm{Cl} 36.5-77.2)$, while those with metastases, $65.1 \%(95 \% \mathrm{Cl} 23.3-88.1)$ and $17.5 \%$ $(95 \% \mathrm{Cl} 1.3-49.7)$, respectively. Figures 2 and 3 show the OS curve of the 41 patients who received neoadjuvant chemotherapy and the differential curves between good and poor responders to neoadjuvant chemotherapy. In Figure 3 does, no statistically significant difference in survival curves is observed. 
Table 2. Outcomes of the 41 patients who received neoadjuvant chemotherapy

\begin{tabular}{|c|c|c|}
\hline Characteristics & n (\%) & $95 \% \mathrm{CI}$ \\
\hline Histologic response to & $41(100)$ & \\
\hline Good response & $15(36.6)$ & $49.35-75.66$ \\
\hline $\begin{array}{l}\text { Poor response } \\
\text { (<90\% necrosis) }\end{array}$ & $26(63.4)$ & $22.57-53.08$ \\
\hline Relapses & 17 (41.4) & $28.63-55.45$ \\
\hline \multicolumn{3}{|l|}{ Relapse sites } \\
\hline Lung & $13(31.7)$ & $20.1-45.7$ \\
\hline Combined & $3(7.3)$ & $2.2-18.5$ \\
\hline Local & $1(2.4)$ & $0.10-12.0$ \\
\hline Deaths & $8(19.5)$ & $10.4-32.7$ \\
\hline \multicolumn{3}{|l|}{ Causes of death } \\
\hline Progression or relapse & $8(19.5)$ & $10.4-32.7$ \\
\hline Infection & 0 & 0 \\
\hline
\end{tabular}

$\mathrm{Cl}$, confidence interval.
Table 3. Overall and event-free survival rates of patients who received neoadjuvant therapy according to histologic response and presence of metastases at diagnosis

\begin{tabular}{|c|c|c|c|}
\hline Characteristics & $\mathbf{n}$ & $\mathrm{HR}^{*}$ & $95 \%$ CI \\
\hline $\begin{array}{l}\text { Comparison of overall survival at } \\
5 \text { years }\end{array}$ & 41 & & \\
\hline $\begin{array}{l}\text { Patients with metastases at } \\
\text { diagnosis }\end{array}$ & 13 & 1.36 & $0.32-5.73$ \\
\hline $\begin{array}{l}\text { Patients with good response to } \\
\text { neoadjuvant chemotherapy }\end{array}$ & 17 & 0.21 & $0.02-1.74$ \\
\hline $\begin{array}{l}\text { Comparison of event-free survival at } \\
5 \text { years }\end{array}$ & 41 & & \\
\hline $\begin{array}{l}\text { Patients with metastases at } \\
\text { diagnosis }\end{array}$ & 13 & 2.15 & $0.82-5.61$ \\
\hline $\begin{array}{l}\text { Patients with a good response to } \\
\text { neoadjuvant chemotherapy }{ }^{\S}\end{array}$ & 17 & 0.20 & $0.04-0.91$ \\
\hline
\end{tabular}

to preoperative chemotherapy, and adjuvant chemotherapy. Thus, histologic response to preoperative chemotherapy became a predictor of survival ${ }^{25,26}$. In a systematic review of the literature, Anninga et al. confirmed that a good histologic response to neoadjuvant chemotherapy is an important prognostic factor, leading to longer patient survival27.

Although the number of patients is small in this cohort, it can be evidenced that patients with good neoadjuvant response had better 5-year overall and event-free survival (88.8\% and $81.4 \%$ ) compared to patients with a poor response $(66.5 \%$ and $31.4 \%)$, respectively. These findings are consistent with the results published by the EURAMOS-1 group ${ }^{5,15}$, who reported that poor histologic response to neoadjuvant chemotherapy was more associated with poor EFS than good responders. Although the EFS of good and poor responders was not reported, it was published that the risk of presenting an event is higher in poor responders $(\mathrm{HR}=2.13,95 \% \mathrm{Cl} 1.76-2.78)$. Similarly, in a cohort treated without high-dose methotrexate at the INC, Suarez et al. ${ }^{28}$ reported that event-free survival in patients with poor response to neoadjuvant chemotherapy was lower than good responders $(\mathrm{HR}=2.90,95 \% \mathrm{Cl}$ 1.60-5.27).

Metastatic disease at diagnosis is detected in $17-20 \%$ of high-grade osteosarcoma cases. It represents a strong predictor of poor outcome, with remarkably low OS and EFS, as observed in the Cooperative 

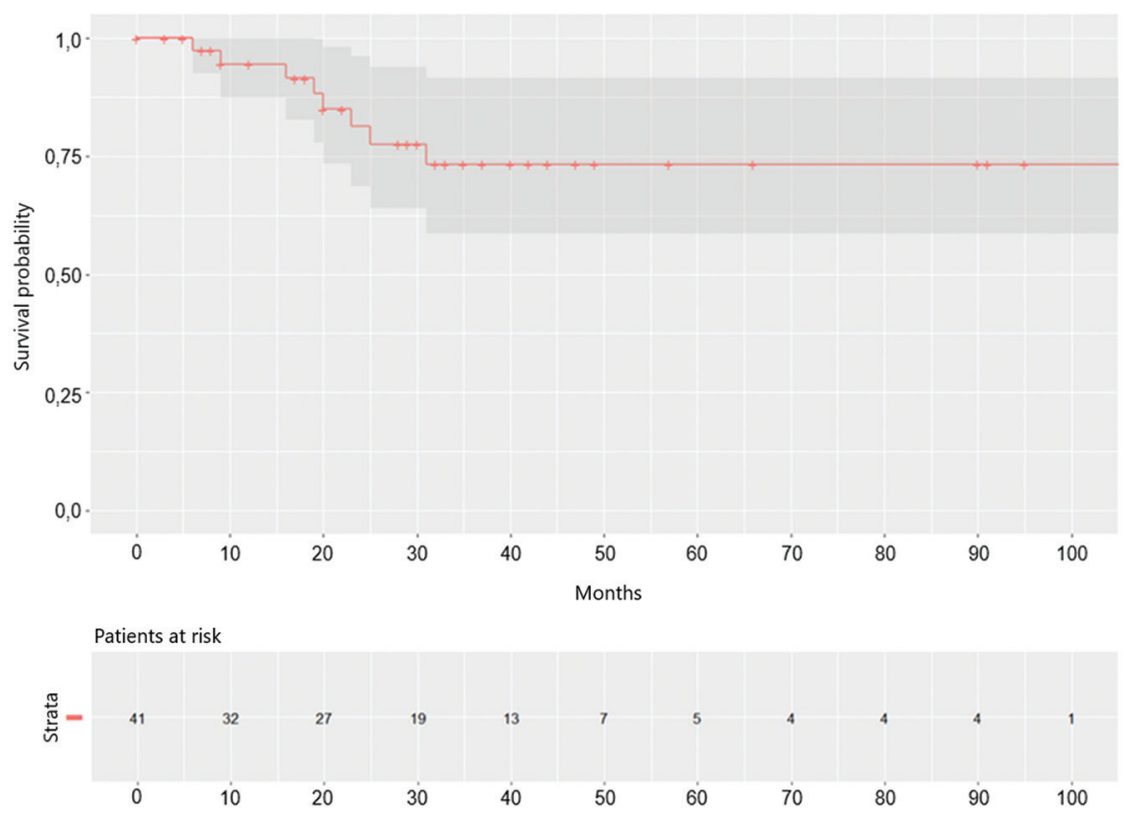

Figure 2. Overall survival (OS) curve for patients who received neoadjuvant chemotherapy. During the first months, the probability of survival decreases and stabilizes at 35 months in $74 \%$. Confidence intervals are plotted in the gray area.

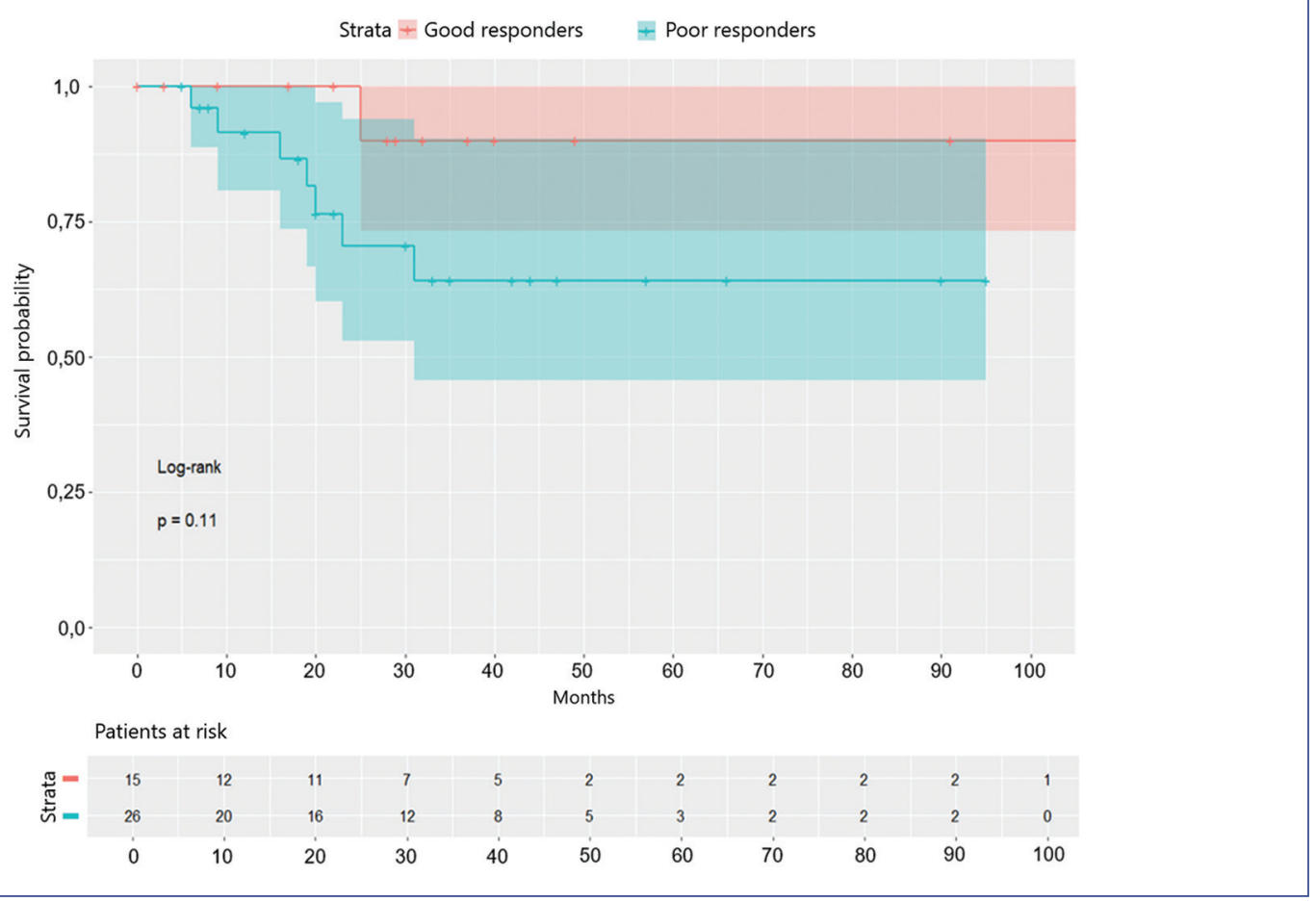

Figure 3. Overall survival (OS) curves according to response to neoadjuvant chemotherapy. The good responder group's survival at 80 months is approximately $88 \%$, compared to $66 \%$ for the poor responder group. However, no statistically significant differences were observed between the two curves. 
German-Austrian-Swiss Osteosarcoma Study Group studies, which showed 5-year and 10-year overall survival of $29 \%$ and $24 \%$, respectively ${ }^{29}$. Bacci et al. found a 5 -year EFS of $18.9 \%{ }^{30}$; more recently, the EURAMOS-1 study achieved 3- and 5-year EFS of $32 \%(95 \% \mathrm{Cl} 27-37)$ and $28 \%(95 \% \mathrm{Cl} 22-33)$. It is noteworthy in our series that metastatic disease is present in $42.8 \%$ of patients at the time of diagnosis, which is slightly more than double that reported by other groups $26,29,30$. However, this situation could be explained because the INC is a reference center for bone tumors. Regardless of the higher number of patients with metastases at diagnosis, 5-year OS and EFS were $25.19(95 \% \mathrm{Cl} 23.32-88.18)$ and $17.58(95 \% \mathrm{Cl} 1.32-49.77)$, respectively, which is very similar to that reported internationally. Finally, although the number of patients who received neoadjuvant chemotherapy was small, the OS (Figure 2) of the cohort stabilized after 34 months of follow-up at $74 \%$, similar to that reported in studies from developed countries ${ }^{26}$.

As limitations of the study, firstly, we can mention that this is a retrospective study conducted with information obtained from INC clinical records, which could imply an information bias in the recording of some variables, such as the imaging measurement of tumor volume, which would have allowed us to evaluate how the relative size of the tumor could influence survival. Secondly, multivariate analysis to determine possible prognostic factors could not be performed because the number of deaths was not high enough to use a Cox proportional-hazards model.

One aspect to highlight is that our results are comparable to clinical trials conducted by international groups with adequate sample sizes and high power. Our findings demonstrate that applying an intense chemotherapy protocol such as OS-INC 2009 is feasible in a developing country as long as it is implemented in pediatric oncology units with the capacity for multidisciplinary management and response to complications caused by complex procedures and administration of drugs with significant toxicity profiles.

In conclusion, evaluation of histologic response to neoadjuvant chemotherapy shows that good responders have better OS and EFS and that pulmonary metastases are a variable that confers the worst vital prognosis in patients with high-grade osteosarcoma.

\section{Ethical disclosures}

Protection of human and animal subjects. The authors declare that no experiments were performed on humans or animals for this study.
Confidentiality of data. The authors declare that they have followed the protocols of their work center on the publication of patient data.

Right to privacy and informed consent. The authors have obtained the written informed consent of the patients or subjects mentioned in the article. The corresponding author has this document.

\section{Conflicts of interest}

The authors declare no conflict of interest.

\section{Funding}

None.

\section{Acknowledgments}

We want to thank the Instituto Nacional de Cancerología (INC).

\section{References}

1. Janeway KA, Randall R, Gorlick R. Osteosarcoma. In: Pizzo PA, Poplack DC, editors. Principles and practices of pediatric oncology. Philadelphia: Wolters Kluwer; 2021. pp. 770-92.

2. Berner K, Johannesen TB, Berner A, Haugland HK, Bjerkehagen B, Bøhler $\mathrm{PJ}$, et al. Time-trends on incidence and survival in a nationwide and unselected cohort of patients with skeletal osteosarcoma. Acta Oncol. 2015:54:25-33.

3. Mirabello L, Troisi RJ, Savage SA. Osteosarcoma incidence and survival rates from 1973 to 2004: data from the surveillance, epidemiology, and end results Program. Cancer. 2009;115:1531-43.

4. Isakoff MS, Bielack SS, Meltzer P, Gorlick R. Osteosarcoma: current treatment and a collaborative pathway to success. J Clin Oncol. 2015;33:3029-35.

5. Marina NM, Smeland S, Bielack SS, Bernstein M, Jovic G, Krailo MD, et al. Comparison of MAPIE versus MAP in patients with a poor response to preoperative chemotherapy for newly diagnosed high-grade osteosarcoma (EURAMOS-1): an open-label, international, randomised controlled trial. Lancet Oncol. 2016;17:1396-408.

6. Marina N, Bielack S, Whelan J, Smeland S, Krailo M, Sydes MR, et al. International collaboration is feasible in trials for rare conditions: the EURAMOS experience. Cancer Treat Res. 2009;152:339-53.

7. Huvos AG, Rosen G, Marcove RC. Primary osteogenic sarcoma: pathologic aspects in 20 patients after treatment with chemotherapy, bloc resection, and prosthetic bone replacement. Arch Pathol Lab Med. 1977;101:14-8.

8. Picci P, Bacci G, Campanacci M, Gasparini M, Pilotti S, Cerasoli S, et al. Histologic evaluation of necrosis in osteosarcoma induced by chemotherapy: regional mapping of viable and non-viable tumor. Cancer. 1985;56:1515-21.

9. Bacci G, Longhi A, Versari M, Mercuri M, Briccoli A, Picci P. Prognostic factors for osteosarcoma of the extremity treated with neoadjuvant chemotherapy: 15-year experience in 789 patients treated in a single institution. Cancer. 2006;106:1154-61.

10. Pakos EE, Nearchou AD, Grimer RJ, Koumoullis HD, Abudu A Bramer JA, et al. Prognostic factors and outcomes for osteosarcoma: an international collaboration. Eur J Cancer. 2009;45:2367-75.

11. Lewis IJ, Nooij MA, Whelan J, Sydes MR, Grimer R, Hogendoorn PC, et al. Improvement in histologic response but not survival in osteosarcoma patients treated with intensified chemotherapy: a randomized phase III trial of the European Osteosarcoma Intergroup. J Natl Cancer Inst. 2007;99:112-28

12. Bramwell VH, Burgers $M$, Sneath $R$, Souhami $R$, van Oosterom AT, Voûte PA, et al. A comparison of two short intensive adjuvant chemotherapy regimens in operable osteosarcoma of limbs in children and young adults: the first study of the European Osteosarcoma Intergroup. J Clin Oncol. 1992;10:1579-91. 
13. Souhami RL, Craft AW, Van der Eijken JW, Nooji M, Spooner D, Bramwell $\mathrm{VH}$, et al. Randomised trial of two regimens of chemotherapy in operable osteosarcoma: a study of the European Osteosarcoma Intergroup. Lancet. 1997:350:911-7.

14. Whelan JS, Jinks RC, McTiernan A, Sydes MR, Hook JM, Trani L, et al. Survival from high-grade localized extremity osteosarcoma: combined results and prognostic factors from three European Osteosarcoma Intergroup randomised controlled trials. Ann Oncol. 2012;23:1607-16

15. Smeland S, Bielack SS, Whelan J, Bernstein M, Hogendoorn P, Krailo MD, et al. Survival and prognosis with osteosarcoma: outcomes in more than 2000 patients in the EURAMOS-1 (European and American Osteosarcoma Study) cohort. Eur J Cancer. 2019;109:36-50.

16. Dahlin DC, Coventry MB. Osteogenic sarcoma. A study of six hundred cases. J Bone Joint Surg Am. 1967:49:101-10.

17. Marcove RC, Mike V, Hajek JV, Levin AG, Hutter RV. Osteogenic sarcoma under the age of twenty-one. A review of one hundred and forty-five operative cases. J Bone Joint Surg Am. 1970;52:411-23.

18. Ochs JJ, Freeman Al, Douglass HO Jr, Higby DS, Mindell ER, Sinks LF. cis-Dichlorodiammineplatinum (II) in advanced osteogenic sarcoma. Cancer Treat Rep. 1978;62:239-45.

19. Pratt $C B$, Shanks EC. Doxorubicin in treatment of malignant solid tumors in children. Am J Dis Child. 1974;127:534-6.

20. Jaffe N, Prudich J, Knapp J, Wang YM, Bowman R, Cangir A, et al. Treatment of primary osteosarcoma with intra-arterial and intravenous high-dose methotrexate. J Clin Oncol. 1983;1:428-31.

21. Link MP, Goorin AM, Miser AW, Green AA, Pratt CB, Belasco JB, et al. The effect of adjuvant chemotherapy on relapse-free survival in patients with osteosarcoma of the extremity. N Engl J Med. 1986;314:1600-6.

22. Eilber F, Giuliano A, Eckardt J, Patterson K, Moseley S, Goodnight J. Adjuvant chemotherapy for osteosarcoma: a randomized prospective trial. J Clin Oncol. 1987;5:21-6
23. Rosen G, Murphy ML, Huvos AG, Gutierrez M, Marcove RC. Chemotherapy, en bloc resection, and prosthetic bone replacement in the treatment of osteogenic sarcoma. Cancer. 1976;37:1-11.

24. Rosen G, Marcove RC, Caparros B, Nirenberg A, Kosloff C, Huvos AG. Primary osteogenic sarcoma: the rationale for preoperative chemotherapy and delayed surgery. Cancer. 1979;43:2163-77.

25. Bacci G, Avella M, Brach Del Prevert A, Capanna R, Fiorentini G, Malaguti $C$, et al. Neoadjuvant chemotherapy for osteosarcoma of the extremities. Good response of the primary tumor after preoperative chemotherapy with high-dose methotrexate followed by cisplatinum and adriamycin. Preliminary results. Chemioterapia. 1988;7:138-42.

26. Whelan JS, Bielack SS, Marina N, Smeland S, Jovic G, Hook JM, et al EURAMOS-1, an international randomised study for osteosarcoma: results from pre-randomisation treatment. Ann Oncol. 2015;26:407-14.

27. Anninga JK, Gelderblom H, Fiocco M, Kroep JR, Taminiau AH. Hogendoorn PCW, et al. Chemotherapeutic adjuvant treatment for osteosarcoma: where do we stand? Eur J Cancer. 2011;47:2431-45.

28. Suárez A, Soto C, Gómez L, Gamboa O, Soto D, Escandón S, et al. Resultados del tratamiento de osteosarcoma convencional de alto grado en niños y adolescentes: análisis de supervivencia de una cohorte tratada sin metotrexato. Rev Colomb Cancerol. 2017;21:86-94.

29. Kager L, Zoubek A, Potschger U, Kastner U, Flege S, Kempf-Bielack B, et al. Cooperative German-Austrian-Swiss Osteosarcoma Study G. Primary metastatic osteosarcoma: presentation and outcome of patients treated on neoadjuvant Cooperative Osteosarcoma Study Group protocols. J Clin Oncol. 2003;21:2011-8.

30. Bacci G, Rocca M, Salone M, Balladelli A, Ferrari S, Palmerini E, et al. High grade osteosarcoma of the extremities with lung metastases at presentation: treatment with neoadjuvant chemotherapy and simultaneous resection of primary and metastatic lesions. J Surg Oncol. 2008:98:415-20 